\title{
Body fat in lean and overweight women estimated by six methods
}

\author{
BY G. MCNEILL $L^{1}$, P. A. FOWLER ${ }^{2 *}$, R. J. MAUGHAN ${ }^{3}$, B. A. MCGAW ${ }^{1}$, \\ M. F. FULLER ${ }^{1}$, D. GVOZDANOVIC ${ }^{2}$ AND S. GVOZDANOVIC ${ }^{2}$ \\ ${ }^{1}$ Rowett Research Institute, Greenburn Road, Bucksburn, Aberdeen AB2 9SB \\ ${ }^{2}$ Department of Bio-medical Physics and Bio-engineering, University of Aberdeen, Forresterhill, \\ Aberdeen $A B 2$ 9ZD \\ ${ }^{3}$ Department of Environmental and Occupational Medicine, University of Aberdeen, Forresterhill, \\ Aberdeen $A B 2$ 9ZD
}

(Received 2 July 1990-Accepted 1 October 1990)

\begin{abstract}
Body fat content of seven lean women (body mass index (BMI) $20.6(\mathrm{SD} 1.8) \mathrm{kg} / \mathrm{m}^{2}$ ) and seven overweight women (BMI $31 \cdot 1$ (sD 3.3) kg/m²) was estimated by six different methods: underwater weighing (UWW), body-water dilution (BWD), whole-body counting $\left({ }^{40} \mathrm{~K}\right)$, skinfold thickness (SFT), bioelectrical impedance (BEI) and magnetic resonance imaging (MRI). Using UWW as the reference method, the differences between percentage fat by each other method and the percentage fat by UWW were calculated for each subject. The mean difference was lowest for SFT and highest for BWD. MRI showed the lowest variability in individual results, and ${ }^{40} \mathrm{~K}$ the highest. ${ }^{40} \mathrm{~K}$ and $\mathrm{BWD}$ methods used in combination gave better agreement with UWW results than either ${ }^{40} \mathrm{~K}$ or BWD methods alone. There was a weak negative correlation between the difference from the UWW results and percentage fat in the SFT measurements, but not in the BWD, ${ }^{40} \mathrm{~K}, \mathrm{BEI}$ or MRI measurements, suggesting that for these methods the assumptions involved produced no greater inaccuracy in the overweight women than in the lean women. In all subjects the BEI offered little improvement over the traditional SFT measurements. The agreement between MRI and UWW estimates in both lean and overweight women suggests that MRI may be a satisfactory substitute for the more established methods of body fat estimation in adult women.
\end{abstract}

Body composition: Methodology : Obesity

Estimates in vivo of body fat content in man are made in a wide variety of research and practical situations, such as the assessment of normal and abnormal growth and standardization of metabolic measurements. Until the last 10 years the majority of estimates relied on underwater weighing (UWW), body-water dilution (BWD) or wholebody counting $\left({ }^{40} \mathrm{~K}\right)$, or on the relationship between skinfold thickness (SFT) and body density (Durnin \& Womersley, 1974). All these methods are limited by assumptions of relationships between the different compartments of the body, which in reality are likely to vary between and possibly within individuals. UWW has often been accepted as the method of choice, although the cooperation required and the need for total immersion limit the suitability to particular groups of subjects. Several comparisons of different methods for estimating body fat or fat-free mass have, however, shown considerable disagreement between both individual and group mean results by the accepted methods of UWW, BWD, ${ }^{40} \mathrm{~K}$ and SFT in women (Womersley et al. 1972; Kryzwicki et al. 1974; Webster et al. 1984; Maughan et al. 1988). The aim of the present study was to extend these comparisons by

* Present address: Department of Obstetrics and Gynaecology, University of Aberdeen, Forresterhill, Aberdeen AB2 9ZD. 
including estimates of body fat by the more recent methods of bio-electrical impedance (BEI) and magnetic resonance imaging (MRI) in both lean and overweight women.

\section{METHODS}

\section{Subjects and experimental timetable}

Fourteen women were recruited from the Rowett Research Institute volunteer register and from a local slimming group. The women were chosen to provide two groups of seven subjects, one lean and one overweight, with similar mean age and height. The age and other anthropometric characteristics of the subjects are given in Table 1. The mean body mass index (BMI) of the lean subjects was $20.6(\mathrm{SD} 1.8) \mathrm{kg} / \mathrm{m}^{2}$, while that of the overweight group was $31 \cdot 1$ (SD $3 \cdot 3) \mathrm{kg} / \mathrm{m}^{2}$.

On the first morning of the study each woman came to the Rowett Research Institute without having had anything to eat or drink for at least $12 \mathrm{~h}$. Weight was measured to the nearest $0 \cdot 1 \mathrm{~kg}$ on a beam balance scale, with the subject wearing only underwear and a light cotton gown, and height was measured to the nearest $1 \mathrm{~mm}$ using a portable stadiometer. Breakfast with a water content of $400 \mathrm{~g}$ was then provided, and 15-30 min later a baseline venous blood sample was taken. Water containing ${ }^{18} \mathrm{O}$ was then given orally, in an amount proportional to the estimated body water of the subjects (see pp. 96-97). This was followed by a drink of $100 \mathrm{ml}$ tap water. No further food or drink was taken over the next $4 \mathrm{~h}$, and measurements of BEI were made in this period. After $4 \mathrm{~h}$ a second venous blood sample was taken and lunch of the subject's choice was provided. During the afternoon and evening of this or a subsequent day the UWW and MRI measurements were made at Aberdeen Royal Infirmary. All measurements were completed within an average of 4 (range 1-9) d.

\section{$U W W$}

Subjects were weighed before the UWW, wearing a loose cotton gown, to the nearest $0 \cdot 1 \mathrm{~kg}$. They were then weighed underwater while seated on a chair suspended from a steel plate fixed rigidly to the ceiling. Distortion of this plate was measured by four strain gauges arranged to form a Wheatstone bridge circuit, and the amplified output of this circuit was displayed on a pen recorder which was calibrated using known weights. Underwater weight was recorded with the subject's head fully immersed underwater after a forced maximal expiration. At least three and usually six to eight determinations of underwater weight were made after the subject had become familiar with the procedure. Residual lung volume at forced expiration was then determined three or more times by rebreathing from a 3 litre bag of pure oxygen (Wilmore et al. 1980). Body fat ( $\%$ body-weight) was calculated as $((4.95 /$ density $)-4.50) \times 100$ (Siri, 1961).

The difference in body fat between two repeat measures 1-30 d apart in six weight-stable subjects who were thoroughly familiar with the experimental system was on average $+0 \cdot 1$ (range -0.4 to +0.5$) \%$ body fat.

\section{$B W D$}

The subjects were given water containing ${ }^{18} \mathrm{O}$ (approximately $10 \cdot 5 \%$ enrichment) at a dose of $850 \mu \mathrm{g} / \mathrm{l}$ body water predicated from the equation:

$$
\text { body water } \begin{aligned}
(1) & =0 \cdot 1069 \times \text { ht }(\mathrm{cm}) \\
& +0.2466 \times \mathrm{wt}(\mathrm{kg})-2.097 \quad \text { (Watson et al. } 1980) .
\end{aligned}
$$

Enrichment of ${ }^{18} \mathrm{O}$ in the dose and in pre- and post-dose plasma samples was determined by an Aqua-SIRA mass spectrometer (VG Isogas, Middlewich), as described by Wong 
Table 1. Anthropometric details of subjects

\begin{tabular}{|c|c|c|c|c|}
\hline & Age (years) & Wt $(\mathrm{kg})$ & Height (m) & BMI $\left(\mathrm{kg} / \mathrm{m}^{2}\right)$ \\
\hline \multicolumn{5}{|c|}{ Lean subjects } \\
\hline A & 24 & $56 \cdot 1$ & 1.710 & 19.2 \\
\hline B & 41 & $59 \cdot 4$ & 1.726 & 19.9 \\
\hline C & 37 & $48 \cdot 3$ & 1.617 & 18.5 \\
\hline D & 54 & 57.7 & 1.585 & $22 \cdot 3$ \\
\hline E & 29 & $57 \cdot 3$ & 1.701 & $21 \cdot 1$ \\
\hline $\bar{F}$ & 37 & $61 \cdot 3$ & 1.607 & 23.7 \\
\hline $\mathrm{G}$ & 36 & $61 \cdot 1$ & 1.701 & $21 \cdot 1$ \\
\hline Mean & 37 & $57 \cdot 3$ & 1.664 & $20 \cdot 6$ \\
\hline SD & 10 & $4 \cdot 4$ & 0.058 & 1.8 \\
\hline \multicolumn{5}{|c|}{ Overweight subjects } \\
\hline $\mathrm{H}$ & 48 & 78.6 & 1.697 & 27.3 \\
\hline I & 20 & $65 \cdot 7$ & 1.561 & 27.0 \\
\hline $\mathrm{J}$ & 41 & 88.8 & 1.627 & 33.5 \\
\hline $\mathrm{K}$ & 53 & 78.9 & 1.614 & $30 \cdot 2$ \\
\hline $\mathrm{L}$ & 46 & $80 \cdot 2$ & 1.629 & 30.2 \\
\hline M & 27 & 92.5 & 1.621 & 35.2 \\
\hline $\mathrm{N}$ & 25 & 87.9 & 1.598 & $34 \cdot 4$ \\
\hline Mean & 37 & $81 \cdot 8$ & 1.621 & $31 \cdot 1$ \\
\hline SD & 13 & $9 \cdot 0$ & 0.041 & $3 \cdot 3$ \\
\hline
\end{tabular}

BMI, body mass index.

et al. (1984). ${ }^{18} \mathrm{O}$ dilution space was determined by the method of Schoeller et al. (1986), and body water was calculated assuming a $1 \%$ overestimate of body water by ${ }^{18} \mathrm{O}$ (Schoeller et al. 1980). Body fat ( $\%$ body-weight) was calculated assuming $73 \cdot 2 \%$ of the fat-free mass to be water (Pace \& Rathbun, 1945), with the value for weight being adjusted for the weight of gown and underwear, breakfast, and the isotopic and washout water given to each subject.

${ }^{2} \mathrm{H}$ was also given to the subjects, but although the results have been given in an earlier communication (McNeill et al. 1989), the estimates of body fat derived from the ${ }^{2} \mathrm{H}_{2} \mathrm{O}$ dilution were subsequently found to be technically unreliable and are not presented here.

Triplicate measurements of plasma ${ }^{18} \mathrm{O}$ enrichment (expressed as $\mu \mathrm{g} / \mathrm{l}$ ) had coefficients of variation ranging from 0.004 to $0.051 \%$ of the mean value in predose plasma and from 0.012 to $0.069 \%$ in the post-dose plasma.

$$
{ }^{40} K
$$

Measurements of whole-body $\mathrm{K}$ content were made by ${ }^{40} \mathrm{~K}$ counting with a scanning shadow-shield whole-body counter. The counter has four Nal (Ti) detectors $(100 \times 150 \mathrm{~mm}$ diameter), two above and two below the subject. These are screened by $100 \mathrm{~mm}$ lead and $20 \mathrm{~mm}$ steel. Each subject was counted twice, with each measurement lasting $25 \mathrm{~min}$. The sensitivity calibration was provided by counting anthropomorphic bottle phantoms of variable size filled with potassium chloride solution. The size of the phantom was matched to that of the subject to within $5 \mathrm{~kg}$ : for overweight subjects the active volume of the phantom was equal to the estimated lean mass of the subject and the weight difference was made up by a layer of pure water surrounding the active volume. This technique has been found to agree with results for absorption of ${ }^{40} \mathrm{~K}$ radiation determined by ${ }^{42} \mathrm{~K}$ counting (Gvozdanovic \& Gvozdanovic, 1987). Background radiation was counted on the same day as the ${ }^{40} \mathrm{~K}$ measurement, using plain water phantoms of similar weight to that of the 
phantom used for each subject: days with increased atmospheric radon levels were not used for counting. The mean values of total body $\mathrm{K}$ were used to estimate body fat assuming $60 \mathrm{mmol} \mathrm{K} / \mathrm{kg}$ fat-free mass (Garrow, 1988).

The coefficient of variation (\%) of the duplicate counts for the subject, background and $\mathrm{KCl}$ phantoms were on average 1.26 (range 1.15-1.52), 1.14 (range 0.92-1.19), and 0.73 (range 0.66-0.88) respectively. These differences lead to a standard error of a single estimate of total body $\mathrm{K}$ of, on average, 8.6 (range $6 \cdot 3-11 \cdot 1$ ) $\%$ of the mean value.

\section{SFT}

Measurements of SFT were made to the nearest $0.2 \mathrm{~mm}$ by one observer $(\mathrm{GMcN})$ using Holtain skinfold calipers. Biceps, triceps, subscapular and supra-iliac skinfolds were measured in triplicate on the left side of the subject at the sites described by Durnin \& Womersley (1974), and the equations given by these authors were used to estimate body fat content from the skinfold thickness measurements.

Repeat measures of body fat by the same observer in nine women of widely varying body fat measured $12 \mathrm{~d}$ apart on a weight-maintaining diet differed by on average $-0 \cdot 3$ (range $-4 \cdot 1$ to $+1 \cdot 2) \%$ body fat.

\section{$B E I$}

A tetra-polar bio-electrical impedance analyser (BMR 2000: Berkeley Medical Systems, California, USA) was used to measure the subjects after breakfast on the first morning of the study. Two measurements were made which were separated by at least $30 \mathrm{~min}$. The analyser uses measurements of upper, middle and lower body impedance to an alternating current of $20-100 \mathrm{kHz}$ in conjunction with measurements of twelve anthropometric variables to estimate body fat content. The assumptions used in the calculation have not been made available by the manufacturers.

The duplicate measures of body fat by BEI in these subjects differed on average by +0.4 (range -0.7 to +2.5 ) \% body fat. The mean of the two values for each subject was used as the value for body fat content by BEI.

\section{$M R I$}

MRI of twenty-eight transverse sections of the body (twenty-one sections between the sternal notch and the upper border of the patella, three along the arms and four between the patella and ankle) were made using a whole-body NMR imager (Redpath et al. 1987). The imager operates at $0.08 \mathrm{~T}$ and a fast inversion recovery sequence which takes $47 \mathrm{~s}$ to collect and which gives good discrimination between fat and lean tissues (Foster et al. 1984; Fowler et al. 1990a) was used. In subjects A, B, I and L only seventeen sections were measured, but no significant difference between estimates of body fat from seventeen or twenty-eight sections was found in the other ten subjects ( $P>0.05$ by ANOVA). Estimates of adipose tissue area in each section were calculated using a semi-automated thresholding technique, and the results corrected for an overestimate of $9.2 \%$ determined by imaging a test object of animal tissue of which the adipose tissue was subsequently determined by weighing. Estimates of total body adipose tissue volume were made using a truncated cone model (Kvist et al. 1988) and body fat was calculated assuming that adipose tissue contains $78.3 \%$ lipid in lean subjects and $83.2 \%$ in obese subjects (Garrow, 1974). This method has been validated by animal carcass studies (Fowler et al. 1990 b) and has been shown to measure tissue volumes accurately. (For precise details of the MRI method used in these subjects see Fowler et al. 1991.)

Repeated measures of adipose tissue content in a test object of animal tissue using this method agreed to $4 \cdot 3$ (SD $2 \cdot 7$ ) \% of mean volume. 


\section{Combined $B W D$ and ${ }^{40} K$ method $(W+K)$}

The results of the estimates of body water and whole-body $\mathrm{K}$ obtained in the present study were used to estimate body fat by a combined method suggested by Bruce et al. (1980) which is designed to take into account assumptions inherent in both methods. Body fat is calculated from the equation:

$$
\text { body fat }(\mathrm{kg})=\text { weight }-(0.12 \times \mathrm{NBW}+0.75 \times \mathrm{BCM}+(\mathrm{TBW}-\mathrm{BCM})) \text {, }
$$

where NBW is 'normal' body-weight-for-height, BCM is body cell mass $(\mathrm{kg})$, calculated as $8.33 \times$ total body $\mathrm{K}(\mathrm{mol})$, and TBW is body water (1).

\section{Statistical analysis}

The agreement between the estimates of percentage body fat by BWD, SFT, BEI and MRI are compared with the estimates by UWW according to the method described by Bland \& Altman (1986). This approach is based on calculation of the difference between the estimate of percentage body fat by the method in question and by UWW for each subject, and on investigation of the relationship between this difference and the average of the estimates by the method and by UWW.

\section{RESULTS}

Table 2 shows the estimates of body fat for each subject by the six methods. Using the UWW results as a reference, it can be seen that the body fat contents of the subjects lay in a continuous range, with the percentage fat of subject $D$ in the lean group higher than that of subject I in the overweight group in spite of her BMI being only $22 \cdot 3 \mathrm{~kg} / \mathrm{m}^{2}$. There were large differences between the individual results by the different methods in both lean and overweight groups, the greatest difference being between SFT and UWW in the subject with the highest body fat by UWW (subject $M$ ). Compared with UWW, the BWD, ${ }^{40} \mathrm{~K}$ and MRI results overestimated body fat content in both lean and overweight groups, while BEI underestimated body fat content in both groups. SFT results were higher than those of UWW in the lean group and lower than those of UWW in the overweight group, notably in the subjects with the highest body fat content (subjects $\mathrm{K}$ and $\mathbf{M}$ ).

Fig. 1 shows the difference between UWW and each of the five other methods for each subject, plotted against the body fat content. Also shown are the results by the $\mathrm{W}+\mathrm{K}$ calculations and the mean difference and its standard deviation for each of the methods. BWD results showed the largest mean difference from the UWW measurements, and a variability similar to that seen in SFT and BEI results. ${ }^{40} \mathrm{~K}$ results showed a mean value more close to the mean UWW value but the highest variability for individual measurements, while SFT measurements showed the smallest mean difference from UWW, but high variability in individual differences. BEI results showed a larger mean difference from UWW than SFT, and the variability in individual measurements was similar to that in BWD and SFT. MRI showed a mean difference intermediate between SFT and BWD measurements, but a lower variability in individual differences than in the other three measurements. The combined $\mathrm{W}+\mathrm{K}$ method gave a mean difference and a variability of differences from UWW between individuals which was less than either the BWD or the ${ }^{40} \mathrm{~K}$ methods alone.

Fig. 1 also shows that there was little evidence of a relationship between the difference from UWW and the body fat content for any of the six methods. In the SFT measurements the two subjects with the highest body fat content showed a greater tendency to underestimation of body fat content than the remaining subjects, which may reflect the difficulty of obtaining accurate skinfold measurements in subjects with high body-fat 
Table 2. Estimates of body fat by underwater weighing ( $U W W$, body water dilution (BWD), whole body counting $\left({ }^{40} K\right)$, skinfold thickness (SFT), bio-electrical impedance $(B E I)$, magnetic resonance imaging $(M R I)$ and a combined method $(W+K)$ in lean and overweight women*

\begin{tabular}{|c|c|c|c|c|c|c|c|c|}
\hline & \multicolumn{7}{|c|}{ Body fat ( $\%$ body-wt) } & \multirow{2}{*}{$\begin{array}{c}\text { Range } \\
(\% \text { body fat })\end{array}$} \\
\hline & UWW & BWD & ${ }^{40} \mathrm{~K}$ & SFT & BEI & MRI & $W+K$ & \\
\hline \multicolumn{9}{|l|}{ Lean } \\
\hline A & 19.6 & $27 \cdot 7$ & $24 \cdot 4$ & $26 \cdot 0$ & $23 \cdot 0$ & $25 \cdot 7$ & 23.4 & $8 \cdot 1$ \\
\hline B & $25 \cdot 0$ & $29 \cdot 4$ & $22 \cdot 0$ & $29 \cdot 3$ & $22 \cdot 5$ & $24 \cdot 9$ & $23 \cdot 1$ & $7 \cdot 4$ \\
\hline $\mathrm{C}$ & 18.8 & 25.9 & $19 \cdot 5$ & 23.8 & 16.5 & $25 \cdot 0$ & $20 \cdot 4$ & $9 \cdot 4$ \\
\hline $\mathrm{D}$ & $37 \cdot 2$ & $38 \cdot 6$ & $33 \cdot 1$ & $36 \cdot 2$ & $29 \cdot 3$ & $36 \cdot 9$ & $34 \cdot 5$ & $9 \cdot 3$ \\
\hline $\mathrm{E}$ & 23.7 & $32 \cdot 9$ & $38 \cdot 4$ & $24 \cdot 2$ & $24 \cdot 6$ & $26 \cdot 6$ & $29 \cdot 3$ & $14 \cdot 7$ \\
\hline $\mathrm{F}$ & $26 \cdot 4$ & $39 \cdot 3$ & 21.9 & $34 \cdot 2$ & 31.5 & $29 \cdot 6$ & 34.0 & $17 \cdot 4$ \\
\hline $\mathrm{G}$ & 26.9 & $26 \cdot 1$ & $34 \cdot 9$ & $26 \cdot 2$ & $25 \cdot 8$ & $28 \cdot 8$ & $24 \cdot 7$ & $10 \cdot 2$ \\
\hline Mean & $25 \cdot 4$ & $31 \cdot 4$ & $27 \cdot 7$ & $28 \cdot 6$ & $24 \cdot 7$ & $28 \cdot 2$ & $27 \cdot 1$ & $10 \cdot 9$ \\
\hline SD & $6 \cdot 1$ & $5 \cdot 7$ & $7 \cdot 5$ & 4.9 & $4 \cdot 9$ & $4 \cdot \overline{2}$ & $5 \cdot 6$ & $3 \cdot 7$ \\
\hline \multicolumn{9}{|c|}{ Overweight } \\
\hline $\mathrm{H}$ & $39 \cdot 6$ & $46 \cdot 7$ & $47 \cdot 5$ & $38 \cdot 4$ & $36 \cdot 7$ & $43 \cdot 8$ & $44 \cdot 3$ & $10 \cdot 8$ \\
\hline $\mathrm{I}$ & 35.8 & $39 \cdot 1$ & $32 \cdot 3$ & $34 \cdot 2$ & $35 \cdot 2$ & $36 \cdot 3$ & $36 \cdot 6$ & 6.8 \\
\hline $\mathrm{J}$ & $43 \cdot 5$ & $51 \cdot 4$ & $52 \cdot 3$ & $41 \cdot 1$ & 43.4 & $47 \cdot 3$ & 50.1 & $10 \cdot 3$ \\
\hline $\mathrm{K}$ & $47 \cdot 4$ & $50 \cdot 5$ & $45 \cdot 1$ & $41 \cdot 2$ & $35 \cdot 1$ & $44 \cdot 1$ & $47 \cdot 7$ & $15 \cdot 4$ \\
\hline $\mathrm{L}$ & $38 \cdot 2$ & $36 \cdot 5$ & $45 \cdot 3$ & $43 \cdot 3$ & 37.6 & $43 \cdot 8$ & $37 \cdot 4$ & 8.8 \\
\hline M & $50 \cdot 0$ & 530 & 42.9 & 40.6 & 48.5 & 48.9 & 50.6 & $12 \cdot 4$ \\
\hline $\mathrm{N}$ & $42 \cdot 1$ & $38 \cdot 5$ & $39 \cdot 0$ & $39 \cdot 6$ & $40 \cdot 4$ & $44 \cdot 4$ & $39 \cdot 2$ & 5.9 \\
\hline Mean & $42 \cdot 4$ & $45 \cdot 1$ & 43.5 & $39 \cdot 8$ & $39 \cdot 6$ & $44 \cdot 1$ & $43 \cdot 7$ & $10 \cdot 1$ \\
\hline SD & $5 \cdot 1$ & $6 \cdot 9$ & $6 \cdot 4$ & 2.9 & 4.9 & $4 \cdot 0$ & 60 & $3 \cdot 3$ \\
\hline
\end{tabular}

* For anthropometric details see Table 1 .

content. The correlation between the difference between SFT and UWW and body fat content was statistically significant $(r-0.7 ; P<0.05)$.

\section{DISCUSSION}

The wide range of values of percentage fat for individual subjects in the present study underlines the observations of other workers that there may be significant differences between results by different methods, even in lean subjects. These differences may arise from errors in the primary data, errors in the assumptions on which the methods are based, or from other biological variation. The possible impact of the assumptions is illustrated by the BWD method: Sheng \& Huggins (1979) have pointed out that the value of $73 \cdot 2 \%$ of fat-free mass as water is based on the average of results which cover a range of at least $70-76 \%$ in most species and which could result in a significant error in the calculation of body fat. It is not possible to assess from these results which of the previously mentioned factors contributes most to the discrepancies seen.

Particularly striking in this set of data is the discrepancy between the UWW and BWD values, which is more marked in the lean group. It is possible that conditions of measurement in the present study, such as the timing of the dilution studies in relation to eating and drinking, introduced some error in the BWD measurements, but the difference between the two methods is consistent with the results of Webster et al. (1984) who found percentage fat by BWD to be $6 \%$ higher than that by UWW in 104 women with varying degrees of obesity. A recent re-analysis of the same data (Garrow et al. 1990) showed that the difference between estimates of fat-free mass by UWW relative to those by BWD and 

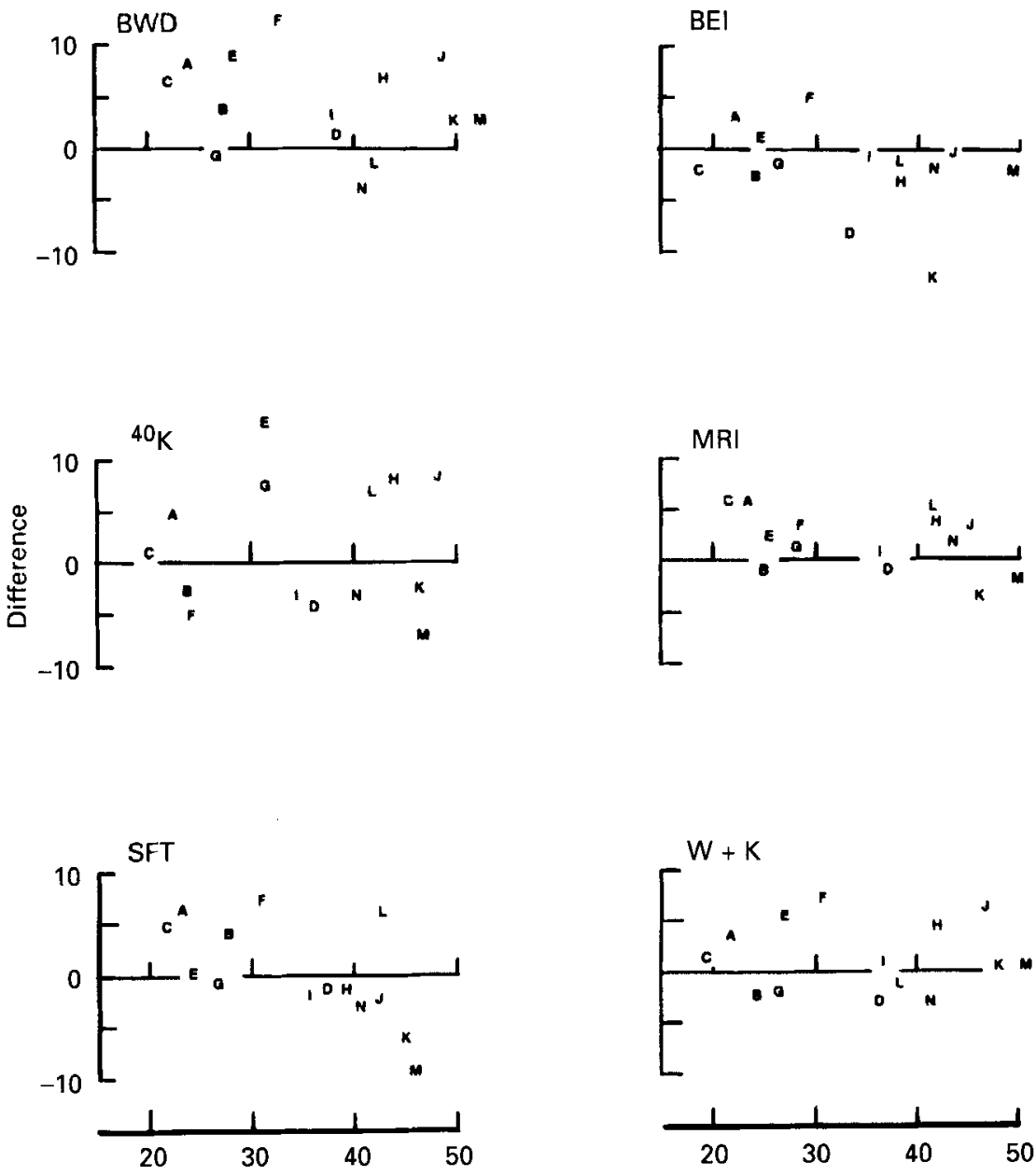

Percentage fat

Fig. 1. Differences between percentage body fat as measured by body water dilution (BWD), whole body counting $\left({ }^{40} \mathrm{~K}\right)$, skin-fold thickness (SFT), bio-electrical impedance (BEI), magnetic resonance imaging (MRI) and a combined method $(\mathrm{W}+\mathrm{K}$ ) and percentage body fat by underwater weighing (UWW) $v$. percentage body fat in fourteen women (subjects A-N). For details of subjects see Table 1, and for details of procedures, see pp. 96-99.

$$
\begin{aligned}
\text { BWD, mean difference }=4.4(\mathrm{SD} \mathrm{4.6)} \% & (r-0.26), \\
{ }^{0} \mathrm{~K}, \text { mean difference }=1.7(\mathrm{SD} 6.7) \% & (r+0.04), \\
\text { SFT, mean difference }=0.3(\mathrm{SD} 4.9) \% & (r-0.70, P<0.05), \\
\text { BEI, mean difference }=-1.7(\mathrm{SD} \mathrm{4.3)} \% & (r-0.31), \\
\text { MRI, mean difference }=2.3(\mathrm{SD} \mathrm{2.9)} \% & (r-0.42), \\
\mathrm{W}+\mathrm{K}, \text { mean difference }=1.5(\text { SD 3.6) } \% & (r-0.01) .
\end{aligned}
$$

${ }^{40} \mathrm{~K}$ were about $6.8 \mathrm{~kg}$, independent of BMI. Our findings also show a similar pattern of estimates in UWW, BWD and ${ }^{40} \mathrm{~K}$ in the lean and overweight groups, but the differences in fat-free mass estimates by $\mathrm{BWD}$ and ${ }^{40} \mathrm{~K}$ were only 2.8 and $1.1 \mathrm{~kg}$ respectively. Pittet et al. (1978) found fat-free mass to be significantly higher (and by inference, body fat $\%$ to be lower) by BWD than by UWW in ten women of similar age and weight to the subjects of the present study, while Lukaski et al. (1981) also found percentage fat to be higher by UWW than by BWD in fourteen young men.

The high variability in the difference between the ${ }^{40} \mathrm{~K}$ measurements and UWW results 
suggest that in this set of data the ${ }^{40} \mathrm{~K}$ method provides the least accurate estimate of body fat for individual subjects. The question must therefore be raised of whether the ${ }^{40} \mathrm{~K}$ results cited here are prone to greater error than results from other centres. The value for the coefficient of variation of the measures of whole-body $\mathrm{K}$ can be compared with a value for the standard error of the estimate of $4 \%$ cited by Morgan \& Burkinshaw (1983), suggesting that our results obtained with a scanning whole-body counter are less reliable than those made with a cubicle and stationary detectors. The improvement in the variability seen when the $\mathrm{BWD}$ and ${ }^{40} \mathrm{~K}$ results are combined suggests that the errors in these methods are due, at least in part, to the assumptions inherent in the models of body compartments used.

The fact that there is little difference between the variability in difference from UWW between SFT and BEI methods suggests that, in this group, BEI has little advantage over the more traditional SFT method other than the lack of need for experience in measurement. By contrast the MRI method shows the lowest variability in difference from UWW, suggesting that the method can be considered as a satisfactory substitute for BWD, ${ }^{40} \mathrm{~K}$, SFT or BEI, at least in women of this age group and degree of overweight. The method has several practical advantages over UWW mentioned previously, but its use is likely to be restricted by the limited availability of the necessary instrumentation and skilled personnel, although this situation is likely to improve as more hospitals invest in MRI equipment.

In summary, these results reinforce the need for caution in the interpretation of estimates in vivo of body fat content and fat-free mass in women. Attempts to standardize other variables such as energy expenditure in relation to these body compartments must also be seen as open to errors in the estimation of both individual and group values for body composition.

The authors thank Scottish Slimmers, Aberdeen, for their help in the recruitment of overweight subjects, Mr G. G. Cameron for assistance in the analysis of the MRI images, and Dr P. Haggarty for advice on calculations in the body water dilution method. Above all they would like to express their thanks to the subjects for their cooperation in the study. P.A.F. was funded by Link-group grant no. LRG 23 from the Agriculture and Food Research Council.

\section{REFERENCES}

Bland, J. M. \& Altman, D. G. (1986). Statistical methods for assessing agreement between two methods of clinical measurement. Lancet i, 307-310.

Bruce, A., Andersson, M., Arvidson, B. \& Isaksson, B. (1980). Body composition. Prediction of normal body potassium, body water and body fat in adults on the basis of body height, body weight and age. Scandinavian Journal of Clinical and Laboratory Investigation 40, 461-473.

Durnin, J. V. G. A. \& Womersley, J. (1974). Body fat assessed from total body density, and its estimation from skinfold thickness. British Journal of Nutrition 32, 77-97.

Foster, M. A., Hutchison, J. M. S., Mallard, J. R. \& Fuller, M. F. (1984). Nuclear magnetic resonance pulse sequence and discrimination of high- and low-fat tissues. Magnetic Resonance Imaging 2, 187-197.

Fowler, P. A., Casey, C. E., Cameron, G. G., Foster, M. A. \& Knight, C. H. (1990a). Cyclic changes in composition and volume of the breast during the menstrual cycle, measured by magnetic resonance imaging. British Journal of Obstetrics and Gynaecology 97, 595-602.

Fowler, P. A., Knight, C. H., Cameron, G. G. \& Foster, M. A. (1990b). Use of magnetic resonance imaging in the study of goat mammary glands in vivo. Journal of Reproduction and Fertility 89, 359-366.

Fowler, P. A., Fuller, M. F., Glasbey, C. A., Cameron, G. G., McNeill, G. \& Maughan, R. J. (1991). Total and subcutaneous adipose tissue in women: the measurement of distribution and accurate prediction of quantity using magnetic resonance imaging (MRI). American Journal of Clinical Nutrition (In the Press).

Garrow, J. S. (1974). Energy Balance and Obesity in Man. Amsterdam: Elsevier/North Holland.

Garrow, J. S. (1988). Obesity and Eating Disorders. London: Churchill Livingstone.

Garrow, J. S., Garby, L. \& Lammert, O. (1990). Comparison of estimates of fat-free mass in normal and obese women from measurements of body potassium, body water and body density. European Journal of Clinical Nutrition 44, 213-217. 
Gvozdanovic, S. \& Gvozdanovic, D. (1987). Total body potassium measurements in subjects of 'abnormal' body shapes. Hospital Physicists Association Proceedings of 44th Annual Conference, Liverpool, p. 40. London: Hospital Physicists' Association.

Kryzwicki, H. J., Ward, G. M., Rahman, D. P., Nelson, R. A. \& Consolazio, C. F. (1974). A comparison of methods for estimating human body composition. American Journal of Clinical Nutrition 27, 1380-1385.

Kvist, H., Chowdhury, B., Sjostrom, L., Tylen, U. \& Cederblad, A. (1988). Adipose tissue volume determination in males by computed tomography and ${ }^{40} \mathrm{~K}$. International Journal of Obesity 12, 249-266.

Lukaski, H. C., Mendez, J., Buskirk, E. R. \& Cohn, S. H. (1981). A comparison of methods of assessment of body composition including neutron activation analysis of total body nitrogen. Metabolism 30, 777-782.

McNeill, G., Fowler, P. A., Maughan, R. J., McGaw, B. A., Gvozdanovic, S., Gvozdanovic, D. \& Fuller, M. F. (1989). Body fat in lean and obese women measured by six methods. Proceedings of the Nutrition Society 48 , $23 \mathrm{~A}$.

Maughan, R. J., Haggarty, P., McGaw, B. A., Gvozdanovic, D. \& Gvozdanovic, S. (1988). Measurement of body composition in lean athletic women. Proceedings of the Nutrition Society 47, 112A.

Morgan, D. B. \& Burkinshaw, L. (1983). Estimation of non-fat body tissues from measurements of skinfold thickness, total body potassium and total body nitrogen. Clinical Science 65, 407-414.

Pace, N. \& Rathbun, E. N. (1945). Studies on body composition. III. The body water and chemically combined nitrogen content in relation to fat content. Journal of Biological Chemistry 158, 685-691.

Pittet, P. G., Stalley, S. F., Hesp, R. \& Halliday, D. (1978). Body composition of women assessed by five methods. Proceedings of the Nutrition Society 37, 86A.

Redpath, T. W., Hutchison, J. M. S., Eastwood, L. M., Selbie, R. D., Johnson, G., Jones, R. A. \& Mallard, J. R. (1987). A low field NMR imager for clinical use. Journal of Physics and Electronics: Scientific Instrumentation 20, 1228-1234.

Schoeller, D. A., Ravussin, E., Schutz, Y., Acheson, K. J., Baertschi, P. \& Jequier, E. (1986). Energy expenditure by doubly labelled water: validation in humans and proposed calculation. American Journal of Physiology $\mathbf{2 5 0}$, R823-R860.

Schoeller, D. A., van Santen, E., Peterson, D. W., Dietz, W., Jaspan, J. \& Klein, P. D. (1980). Total body water measurement in humans with ${ }^{18} \mathrm{O}$ and ${ }^{2} \mathrm{H}$ labelled water. American Journal of Clinical Nutrition 33, 2686-2693.

Sheng, H.-P. \& Huggins, R. A. (1979). A review of body composition studies with emphasis on total body water and fat. American Journal of Clinical Nutrition 32, 630-647.

Siri, W. E. (1961). In Techniques for Measuring Body Composition, pp. 223-245 [J. Brozek \& A. Henschel, editors]. Washington, DC: National Academy of Science/National Research Council.

Watson, P. E., Watson, I. D. \& Batt, R. D. (1980). Total body water volumes for adult males and females estimated from simple anthropometric measurements. American Journal of Clinical Nutrition 33, 27-39.

Webster, J. D., Hesp, R. \& Garrow, J. S. (1984). The composition of excess weight in obese women, estimated by body density, total body water and total body potassium. Human Nutrition: Clinical Nutrition 38C, 299-306.

Wilmore, J. H., Vodak, P. A., Parr, R. B., Girandola, R. N. \& Billing, J. E. (1980). Further simplification of a method for determination of residual lung volume. Medicine and Science in Sports and Exercise 12, 216-218.

Womersley, J., Boddy, K., King, P. L. \& Durnin, J. V. G. A. (1972). A comparison of the fat-free mass of young adults estimated by anthropometry, body density and total body potassium content. Clinical Science $\mathbf{4 3}$, 469-475.

Wong, W. W., Cabrera, M. P. \& Klein, P. D. (1984). Evaluation of a new dual mass spectrometer system for rapid simultaneous determination of ${ }^{2} \mathrm{H} /{ }^{1} \mathrm{H}$ and ${ }^{18} \mathrm{O} /{ }^{16} \mathrm{O}$ ratios in aqueous samples. Analytical Chemistry 56, $1852 \cdots 1858$. 